\title{
Microcosm Experiments as a Tool in Soil Ecology Studies
}

\author{
Roxana VIDICAN, Valentina SANDOR* \\ ${ }^{1}$ Faculty of Agriculture, University of Agricultural Sciences and Veterinary Medicine Cluj-Napoca, \\ Manastur St., 400372 Cluj-Napoca, Romania; \\ * corresponding author: sandorvalentina@yahoo.com
}

Bulletin USAMV series Agriculture 72(1)/2015

Print ISSN 1843-5246; Electronic ISSN 1843-5386

DOI 10.15835/buasvmcn-agr: 10618

\begin{abstract}
Soil microcosms are also called Terrestrial Model Ecosystems (Carbonell and Tarazona, 2014). There is a large diversity of microcosm studies from simple systems to sophisticated terrestrial ecosystems. Many disciplines have utilized microcosms as a powerful research tool especially microbiologists, ecotoxicologists, limnologists (Fraser et al. 2004) and soil ecologists (Sandor and Schrader, 2012). This study is in attempt of a better understanding terrestrial model ecosystem and some causal effects that can be simulated. For this purpose advantages and drawbacks are assessed. Microcosms can be placed indoor or outdoor using sieved soil or undisturbed cores. Experiments variables have included: moisture supply, soil depth, temperature, mineral nutrient supply, carbon dioxide concentration, mycorrhizae, rhizobia, plants, herbivores and carnivores animals. The time of the study depends on the ecological processes under investigation. All the experimental designs have advantages like the ease of replication and manipulation of the parameters and treatments involved and some disadvantages like restricted space. Further factorial microcosm experiments can explore combinations of factors for a better understanding of causal relationships and interactions between plants species and soil communities. Comparison is helped by separating complex causal effects.
\end{abstract}

Keywords: ecosystems, model, soil.

\section{INTRODUCTION}

Small-scale experimental systems also called microcosms or mesocosms have historically informed understanding of ecological processes that are applicable at larger scales (Carbonell and Tarazona, 2014). Indeed, more recently, the use of microcosms has had a role in exploring the consequences of seemingly insurmountable global issues, such as the effect of climate change on species distributions and food-web structure (Petchey et al. 1999), the effects of biodiversity loss on ecosystem functioning (Balvanera et al. 2006, Sandor and Schrader, 2012), and the impacts of pollution and fisheries on ecosystems (Micheli, 1999) or harvesting on population dynamics (Cameron and Benton, 2004).

Microcosms are basically small ecosystems in containers. There is a high range of microcosm studies from simple experimentally sown mixtures of two species of plants to sophisticated controlled environments housing entire terrestrial ecosystems such as the Ecotron facility at Silwood Park (Naeem et al. 1994). The main role of microcosms is that they act as a bridge between theory and nature. They do not mirror nature but they can increase our understanding of natural processes by simplifying the complexities of our natural environment. Microcosm experiments have played an important role in developing and testing ecological theories and investigating current global change scenarios.

The research assesses some microcosm studies to deepen our understanding of their role in ecological studies.

\section{MATERIALS AND METHODS}

For setting up a microcosm experiment it is necessary to construct some plastic containers 
no smaller than $25 \times 50 \mathrm{~cm}$ (Fraser et al. 2004), to choose the questions that needs investigation, set the time scale and all the other materials depending of the type of the experiment.

\section{RESULTS AND DISCUSSION}

Mortimer (1942) was a pioneer in the use of microcosm systems in limnological investigations. His results were similar to those from his in situ observations in Esthwaite Water. Abbott (1966) described microcosms as miniaturized ecosystems and also noted that, due to the unpredictability and complexity of natural systems, in situ experiment results were often vague and inconclusive, and many researchers had successfully used microcosm systems to simplify experimental conditions in their investigations of natural systems. In addition, he noted that, although microcosms do not reproduce natural systems precisely, they provide the advantage of allowing researchers to investigate under controlled conditions.

In 2006, at University of California-Davis, working with experimental microcosms of protists, the researchers have shown how the effects of disturbance on diversity can be predicted by understanding the traits of species within the community. In Netherlands was set a microcosm experiment with aboveground and belowground herbivores, with the question by which mechanisms belowground herbivores, pathogens or decomposers can influence the interactions between plants, herbivores and parasitoids aboveground, and vice versa.

\section{CONCLUSION}

The advantages of using microcosms include the ease of replication and manipulation of the parameters and treatments involved. However, there are limitations and disadvantages as well when using microcosms, the major one being restricted space. Otherwise, each microcosm experiment will have their own specific advantages and disadvantages according to the researcher's design. The experiments described in this paper demonstrate that microcosms are an important and useful tool in ecological research (Fraser, 1999).

Acknowledgements: This paper was published under the frame of European Social Fund, Human Resources Development Operational Programme 2007-2013, project no. POSDRU/159/ 1.5/S/132765.

\section{REFERENCES}

1. Abbott W (1966). Microcosm studies on estuarine waters 1 . The replicability of microcosms. Water Pollut Control, 38:258-270.

2. Balvanera P, Pfisterer AB, Buchmann N He JS, Nakashizuka T, Raffaelli D,mSchmid B, (2006). Quantifying the evidence for biodiversity effects on ecosystem functioning and services. Ecol. Lett. 9:1146-1156.

3. Cameron, TC, Benton TG (2004). Stage-structured harvesting and its effects: an empirical investigation using soil mites. J. Anim. Ecol. 73:996-1006.

4. Carbonell G, Tarazona JV (2014). Terrestrial microcosms and multispecies soil systems, Encyclopedia of ToxicologyThird Edition, 486-489.

5. Fraser LH, Spring MC, Steer D (2004). A test four plant species to reduce total nitrogen and total phosphorus from soil leachate in subsurface wetland microcosms. Bioresource Technology 94:185-192.

6. Micheli F (1999). Eutrophication, fisheries, and consumerresource dynamics in marine pelagic ecosystems. Science 285:1396-1398.

7. Mortimer CH (1942). The exchange of dissolved substances between mud and water in lakes. J. Ecol. 30:147-201.

8. Naeem S, Thompson L.J, Lawler SP, Lawton JH, Woodfin RM (1994). Declining biodiversity can alter the performance of ecosystems. Nature, 368:734-737.

9. Petchey OL, McPhearson PT, Casey TM, Morin PJ (1999). Environmental warming alters food-web structure and ecosystem function. Nature 402:69-72.

10. Sandor M, Schrader S (2012). Interaction of earthworms and enchytraeids in organically amended soil, NorthWestern Journal of zoology 8(1):46-56. 